\title{
Molecular characterization of ombrotrophic peats by humeomics
}

\author{
Giovanni Vinci ${ }^{1 *}$, Pierluigi Mazzei ${ }^{1}$, Marios Drosos ${ }^{2}$, Claudio Zaccone ${ }^{3}$ and Alessandro Piccolo ${ }^{1 *}$
}

\begin{abstract}
Background: An insight into the molecular composition of ombrotrophic peats of different geographical origin and collected at different depths was achieved by the humeomics method. The humeomic fractionation allowed the separation of molecular components in either organic solvents or water on the basis of their progressive binding strength to the humic matrix. The solubilized matter in fractions was analyzed by gas chromatography-mass spectrometry (GC-MS) or by proton nuclear magnetic resonance ('H NMR) spectroscopy, while the residues depleted of the extracted material were observed by ${ }^{13} \mathrm{C}$ cross-polarization magic-angle-spinning nuclear magnetic resonance $\left({ }^{13} \mathrm{C}\right.$-CPMAS-NMR) spectroscopy.

Results: The analytical characterization of fractions and residues differentiated peats not only on the basis of the different classes of extracted molecules, but also on their binding strength to the complex peat matrix. Aromatic, lipidic, and sugar compounds were the most representative molecular classes extracted in the humeomic fractions and their abundance varied with depth. The distribution and abundance of extracted compounds provided an indication of the extent of organic matter accumulation in peat. The NMR spectra of solid residues supported the interpretation of the characteristics of the various extracts.
\end{abstract}

Conclusions: Our findings proved that the humeomic approach allows to provide important information on both the molecular composition of peats and its variation with depth.

Keywords: Peat, Humus, Organic matter, Humeomics, Fractionation, GC-MS, NMR

\section{Background}

Peat is a naturally occurring heterogeneous material composed by partially degraded organic matter $(\mathrm{OM})$, prevalently deriving from plants residues, which accumulated in a water-saturated environment and in absence of oxygen $[1,2]$. Peatlands are generally characterized by anoxic and acidic or circum-neutral conditions. In particular, "bog" and "fen" represent two opposite types of peatlands (often as described as a continuum) where the variables of vegetation (Sphagnum vs. sedge dominated), chemistry (acidic vs. circum-neutral) and source of water and nutrients

\footnotetext{
*Correspondence: giovanni.vinci@unina.it; alessandro.piccolo@unina.it

${ }^{1}$ Centro Interdipartimentale di Ricerca Sulla Risonanza Magnetica

Nucleare per l'Ambiente, I'Agroalimentare ed i Nuovi Materiali

(CERMANU), Università di Napoli Federico II, Via Università, 100

80055 Portici, NA, Italy

Full list of author information is available at the end of the article
}

(rainfall vs. ground- and surface water) differ markedly [3]. Such relatively adverse conditions lead to the development of selected microbiological communities, adapted to extreme environments, mostly anaerobic, whose degrading action is relatively slow and may be further influenced by site-specific microclimate $[4$, 5]. In fact, decomposer communities, peat-forming plants, water table fluctuation, $\mathrm{pH}$, oxygen availability and temperature strongly affect the degree of decomposition [6-9]. Consequently, OM accumulation in peatlands is commonly favored since the rate of OM production is larger than the decomposition rate [10]. Generally, the greatest decomposition rate is reached in the upper layer of a peat profile because of the relatively more oxic conditions, whereas, in the anoxic zone, peat decomposes very slowly [11]. At a global scale, peatlands serve as a long-term persistent carbon (C) sink, 
having accumulated $>600 \mathrm{GtC}$ over the Holocene [12], and constitute authentic records of information on (paleo) environmental changes [13].

The most common chemical groups usually detected in peats include cellulose, hemicellulose, lignin, protein, cutin and suberin which are mostly derived from plant biopolymers. Therefore, peat is a very heterogeneous and organic C-rich material whose specific molecular composition, as well as its degree of humification, mainly varies according to geographical origin, peat-forming vegetation, and the environmental conditions under which peat was exposed over time but not consistently with age and depth [9].

Several analytical techniques have been applied to elucidate the molecular composition of this complex material. Many of these, including chemolytic methods, are destructive and may produce artifacts, thus preventing a reliable interpretation of results [14]. For example, pyrolysates of peats entail complex interpretations because of molecular rearrangements occurring during pyrolysis. In light of this, ${ }^{13} \mathrm{C}$ cross-polarization magic-angle-spinning nuclear magnetic resonance (CPMAS NMR) spectroscopy represents a non-destructive and useful technique to study peats since it informs on the distribution of different $\mathrm{C}$ groups, thus indicating the most abundant molecular classes composing the peat OM.

Recently, the composition of very complex natural organic materials, such as humic extracts from soils, or directly that of soil OM, was studied by the humeomics procedure $[15,16]$. Humeomics consists in a sequential chemical fractionation that selectively separate humic molecules in several organo- and hydrosoluble fractions which are less heterogeneous that the bulk material and whose molecular characterization becomes hence relatively easier and more complete. The aim of this work was to apply humeomics for the first time to peat samples from different geographical areas and collected at different depths. The resulting fractions and residues were characterized by gas chromatography-mass spectrometry (GC-MS) and NMR spectroscopy at both solid and liquid state.

\section{Methods \\ Peat samples}

The samples used in this study were selected from two peat bog profiles, i.e., one from Queen Charlotte Islands (now Haida Gwaii, Canada; [17]) and one from Etang de la Gruère (Switzerland, core 2T; [18]). For both sites, a monolith, 100-cm-deep core was collected using a Wardenaar sampler and kept frozen at $-18{ }^{\circ} \mathrm{C}$ until analysis. Frozen cores were then sliced into ca. 1 -cm-thick sections. Representative samples for each core were selected at two depths, i.e., Peat-1A and Peat-1B for the Canadian bog, and Peat-2A, Peat-2B for the Swiss bog. Details on samples age dates, ash content, sampling depth and elemental composition are reported in Table 1 . All samples were stored at a controlled temperature $\left(4-6{ }^{\circ} \mathrm{C}\right)$, washed with acidified water $(0.1 \mathrm{M} \mathrm{HCl})$ and dried overnight at $40^{\circ} \mathrm{C}$ before being submitted to the humeomic sequential chemical fractionation.

\section{Humeomic fractionation}

The humeomic fractionation was applied directly on peat samples by following the procedure described earlier [15] with only slight modifications. Briefly, the unbound organosoluble fraction (ORG1) was obtained from the bulk peat material (RES0) by extracting twice by a dichloromethane and methanol solution $(2: 1, \mathrm{v} / \mathrm{v})$ under magnetic stirring for $24 \mathrm{~h}$ at room temperature. The supernatant was separated by centrifugation $(15 \mathrm{~min}$, $7500 \mathrm{rpm}$ ), filtered through a Whatman 41 filter and rotoevaporated to dryness, while the remaining residue (RES1) was air-dried before the next step. The weakly bound organo- and hydrosoluble ester fractions (ORG2 and AQU2) were extracted from RES1 using a transesterification reaction conducted at $80{ }^{\circ} \mathrm{C}$ for $12 \mathrm{~h}$, by adding in a Teflon tube a solution of $12 \% \mathrm{BF}_{3}$ in methanol under $\mathrm{N}_{2}$ atmosphere. The reaction was repeated twice using a

Table 1 Properties and elemental composition of the peat samples

\begin{tabular}{|c|c|c|c|c|c|c|c|c|c|}
\hline Sample & Origin, classification and depth & $\mathrm{Age}^{\mathrm{a}}$ & Ash (\%) & $\mathrm{C}(\%)$ & H (\%) & $\mathrm{N}(\%)$ & $\mathrm{O}(\%)$ & $C / N(w / w)$ & $\mathrm{C} / \mathrm{H}(\mathrm{w} / \mathrm{w})$ \\
\hline $1 \mathrm{~A}$ & $\begin{array}{l}\text { Canadian ombrotrophic peat (Queen Char- } \\
\text { lotte Islands) Depth: ca. } 27 \mathrm{~cm}\end{array}$ & 1904 A.D & 2.56 & $50.43 \pm 0.35$ & $5.78 \pm 0.01$ & $0.78 \pm 0.08$ & 42.39 & 64.6 & 8.7 \\
\hline $1 B$ & $\begin{array}{l}\text { Canadian ombrotrophic peat (Queen Char- } \\
\text { lotte Islands) Depth: ca. } 87 \mathrm{~cm}\end{array}$ & - & 1.06 & $53.91 \pm 2.38$ & $6.40 \pm 0.26$ & $0.51 \pm 0.04$ & 38.71 & 105.7 & 8.4 \\
\hline $2 \mathrm{~A}$ & $\begin{array}{l}\text { Swiss ombrotrophic peat (Etang de la Gruère) } \\
\text { Depth: ca. } 27 \mathrm{~cm}\end{array}$ & 1941 A.D & 2.07 & $48.55 \pm 0.12$ & $5.98 \pm 0.11$ & $0.61 \pm 0.04$ & 44.83 & 79.6 & 8.1 \\
\hline $2 B$ & $\begin{array}{l}\text { Swiss ombrotrophic peat (Etang de la Gruère) } \\
\text { Depth: ca. } 101 \mathrm{~cm}\end{array}$ & са. 2100 B.P & 1.69 & $52.50 \pm 0.30$ & $6.13 \pm 0.04$ & $0.69 \pm 0.01$ & 40.68 & 76.1 & 8.6 \\
\hline
\end{tabular}

a Data from $[17,18]$ 
ratio of $1 \mathrm{~mL}$ of solution per gram of material. The residual $\mathrm{BF}_{3}$ was then quenched with water and the resulting supernatants separated by liquid-liquid extraction in an aqueous phase (AQU2) and a $\mathrm{CHCl}_{3}$ phase (ORG2). The ORG2 fraction was dried with anhydrous $\mathrm{Na}_{2} \mathrm{SO}_{4}$, filtered on a Whatman 41 filter and rotoevaporated to dryness, while the AQU2 fraction was rotoevaporated to remove residual traces of chloroform, dialyzed against distilled water using AmiconC membranes (1000 Da cutoff) and freeze-dried. The remaining solid residue (RES2) was extensively water-washed and freeze-dried for the next step.

The strongly bound ester fractions (ORG3 and AQU3) were extracted from RES2 using a $1 \mathrm{M} \mathrm{KOH}$ solution in methanol under $\mathrm{N}_{2}$ atmosphere for $2 \mathrm{~h}$ at $70{ }^{\circ} \mathrm{C}$ (this step was repeated three times). After cooling, the supernatants were combined, $\mathrm{pH}$ adjusted to 2 with $\mathrm{HCl}$ and then liquid-liquid extracted by dichloromethane and water. The organo-soluble (ORG3) and hydro-soluble (AQU3) extracts were purified as for ORG2 and AQU2, while the RES3 was water-washed and freeze-dried. Finally, the strongly bound ether components (AQU4) were hydrolyzed from RES3 by a $47 \%$ HI solution under $\mathrm{N}_{2}$ atmosphere for $48 \mathrm{~h}$ at $70{ }^{\circ} \mathrm{C}$. The last residue (RES4) was dialyzed against water and freeze-dried. All extraction procedures to isolate the ORG and AQU fractions were made in triplicate.

\section{Nuclear magnetic resonance (NMR) spectroscopy}

${ }^{13} \mathrm{C}$-CPMAS-NMR spectra of residues (RES0 to RES4) were acquired with a wide-bore $300 \mathrm{MHz}(7.0 \mathrm{~T})$ Bruker Avance magnet (Bruker Bio Spin $\mathrm{GmbH}$, Rheinstetten, Germany), equipped with a CPMAS (Cross-Polarization Magic-Angle-Spinning) probe, working at the ${ }^{13} \mathrm{C}$ frequency of $75.47 \mathrm{MHz}$. Dried samples were fitted into $4 \mathrm{~mm}$ zirconia rotors with Kel-F caps and spun at a rate of 13,000 Hz. Each carbon spectrum implied a recycle delay of $2 \mathrm{~s}$ and an acquisition time of $3 \mathrm{~ms}$. All the Free Induction Decays (FID) were Fourier transformed by adopting a fourfold zero-filling and applying the apodization through a $300 \mathrm{~Hz}$ exponential multiplication.

A $400-\mathrm{MHz}$ Bruker Avance spectrometer, equipped with a 5 -mm BBI Bruker probe and working at the ${ }^{1} \mathrm{H}$ frequency of $400.13 \mathrm{MHz}$, was used to obtain liquid state NMR spectra for all water-soluble fractions (AQU). The samples were dissolved in DMSO-d6 into 5.0-mm quartz tubes and the spectra were acquired by pre-saturating the signal of water.

The ${ }^{13} \mathrm{C}$ NMR and ${ }^{1} \mathrm{H}$ NMR spectra were phase and baseline corrected, while the spectral processing was performed by the TOPSPIN software (v. 2.1, Bruker Bio Spin $\mathrm{GmbH}$, Rheinstetten, Germany).

\section{Gas chromatography-mass spectrometry (GC-MS)}

The organo-soluble fractions (ORG1-3) were derivatized before GC-MS analysis using acetyl chloride and methanol as methylating agent, followed by silylation using $\mathrm{N}, \mathrm{Nbis}$ [trimethylsilyl] trifluoroacetamide with $1 \%$ of trimethylchlorosilane. The quantitative data were obtained by external calibration curves using specific standards for the different classes of compounds.

Samples were analyzed using a PerkinElmer (PE) Autosystem XL by using a RTX-5MS WCOT capillary column (Restek, $30 \mathrm{~m} \times 0.25 \mathrm{~mm}$; film thickness, $0.25 \mu \mathrm{m}$ ) that was coupled, through a heated transfer line $\left(250^{\circ} \mathrm{C}\right)$, to a PE Turbomass-Gold quadrupole mass spectrometer. The gas chromatographic separation was performed by applying a 2-min-long isothermal phase at $100^{\circ} \mathrm{C}$, followed by a temperature increase from 100 to $300{ }^{\circ} \mathrm{C}\left(4{ }^{\circ} \mathrm{C} \mathrm{min}{ }^{-1}\right)$ and culminating in a 5-min-long isothermal phase at $300{ }^{\circ} \mathrm{C}$. Helium was used as carrier gas at $1.6 \mathrm{~mL} \mathrm{~min}^{-1}$, as well as the injector temperature was set at $250{ }^{\circ} \mathrm{C}$ and the split flow applied for the split-injection mode was $25 \mathrm{~mL} \mathrm{~min}{ }^{-1}$. Mass spectra were obtained in EI mode $(70 \mathrm{eV})$, scanning in the range included within 50 and $600 \mathrm{~m} \mathrm{z}^{-1}$, with a cycle time of $0.2 \mathrm{scan} \mathrm{s}^{-1}$. The identification of mass spectra of eluted compounds was carried out by analyzing standard compounds as well as by evaluating the mass spectra reported in the library NIST 05 (https://www.nist.gov).

\section{Results and discussion}

\section{Elemental composition}

The elemental composition and a brief description of peat samples collected both in Canada and Switzerland are reported in Table 1 . Peat samples showed slightly different content of $\mathrm{C}, \mathrm{N}, \mathrm{H}$ and $\mathrm{O}$, but these differences were quite small when samples at similar depths were compared ( $1 \mathrm{~A}$ vs. $2 \mathrm{~A}$ and $1 \mathrm{~B}$ vs. $2 \mathrm{~B})$. Both the $\mathrm{C} / \mathrm{N}$ and the $\mathrm{C} / \mathrm{H}$ ratios (Table 1 ), that are generally used as humification proxies, $[5,9,19,20]$, underline an opposite peat evolution trend throughout the two profiles.

\section{Gravimetric evaluation of peat organic matter after humeomic extraction}

The gravimetric evaluation of the OM separated in each step of the humeomic fractionation indicates that the most abundant extraction yields were those of fractions ORG1, ORG2 and AQU2 (Table 2). These fractions represented, respectively, the unbound humic matter (ORG1 fraction) and the weakly ester bound humic molecules (ORG2 and AQU2 fractions). In both sites, the yields of ORG1 fractions in sample $1 \mathrm{~B}$ and $2 \mathrm{~B}$ increased with depth and resulted 52 and $61 \%$ larger than the surface 
layers (1A and $2 \mathrm{~A}$ ), respectively. The ORG2 fraction showed the largest extraction yields, although no significant correlation was observed with the sample depth. For the $1 \mathrm{~A}, 1 \mathrm{~B}$ and $2 \mathrm{~A}$ peat samples, the extraction yield of ORG2 was 158, 59 and $48 \%$ greater than for ORG1, respectively, whereas in peat $2 \mathrm{~B}$ the ORG1 fraction yield was 78\% larger than for ORG2 (Table 2).

When both ORG2 and AQU2 fractions are considered together, a differentiation between the two sites becomes more evident. In fact, the extractive average of ORG2 + AQU2 in $1 \mathrm{~A}$ and $1 \mathrm{~B}$ peats was $26.8 \%$ and $28.9 \%$, respectively, whereas it was only 17.9 and $20.2 \%$ in peat $2 \mathrm{~A}$ and $2 \mathrm{~B}$, respectively. This difference in extraction yields suggests that molecules present in esters weakly bound to the complex humic superstructure were more abundant in peat 1 than in peat 2. A difference between the two sites resulted also by the extraction yields of both ORG3 and AQU3 fractions, which were 2.7 and $0.6 \%$ for $1 \mathrm{~A}$ and $1 \mathrm{~B}$, and 2.3 and $1.4 \%$ for $2 \mathrm{~A}$ and $2 \mathrm{~B}$, respectively. Therefore, the solubiliation of molecules held in strongly bound esters was also slightly more efficient for the Canadian peat and decreased with depth for both peatlands. Possibly because peat 1 was depleted of humic compounds solubilized more extensively in previous fractions, the extraction of molecules bound in ether linkages (ORG4 + AQU4 fractions) resulted larger than in peat 2, reaching $10.8 \%$ in $1 \mathrm{~A}$ and only $4.3 \%$ in $2 \mathrm{~A}$. Also the yields of the ether-bound molecules differed with sample depth in the two profiles, being $5.2 \%$ in $1 \mathrm{~B}$ and only $2.3 \%$ in $2 \mathrm{~B}$ (Table 2).

Such lesser chemical stabilization of humic suprastructures in the Canadian peat compared to the Swiss peat was also revealed by the percent weight of organic $\mathrm{C}$ remained in RES4 after the humeomic fractionation. In fact, the former peat showed 12.3 and $15.7 \%$ for the surface and bottom layers, whereas the latter peat resulted in larger values (30 and 24.7\%, respectively) (Table 2).

Notwithstanding the greater stability of the humus matrix of the Swiss peat, the weight of the unaccounted material at the end of the fractionation (UM in Table 2) was similar for both sites, ranging from 37 to $41 \%$, and in line with previous reports on material losses during humeomics [15]. These losses should be probably attributed to decarboxylation reactions, release of volatile substances, and dispersion of low molecular-size hydrophilic components during dialysis processes.

\section{RES characterization by ${ }^{13} \mathrm{C}$-CPMAS-NMR}

The ${ }^{13}$ C-CPMAS-NMR spectra (Fig. 1) allowed to calculate the relative $\mathrm{C}$ distribution (Table 3) over the chemical shift regions in peat samples before (RES0) and after the humeomic fractionation (RES 1-4). Spectra of RES0 revealed a similar composition in all peat samples, except for a significant increase of signals in the alkyl-C region $(0-45 \mathrm{ppm})$ in the bottom horizon of both peatlands (Fig. 1). In fact, the abundance of that region increased with depth by 10 and $260 \%$ for the Canadian and Swiss peat, respectively (Fig. 1, Table 3 ). These signals were assigned to lipidic compounds, plant waxes, and biopolyesters, represented by the intense signal in the $20-35 \mathrm{ppm}$ range and ascribable to methylenic and methyl groups in alkyl chains [21]. All RES0 spectra (Fig. 1) were characterized by a strong predominance of O-alkyl carbons (60-110 ppm) attributed mainly to oligo- and polysaccharidic chains of plant woody tissues [22], whose signals decreased with depth in both peatlands but to a larger extent in the Swiss bog (peat 2) (Table 3). In particular, the broad and intense signal region at around $73 \mathrm{ppm}$ was assigned to the overlapping signals of $\mathrm{C}-2, \mathrm{C}-3$, and $\mathrm{C}-5$ carbons in pyranosidic structures of cellulose and hemicelluloses, whereas the signal at $105 \mathrm{ppm}$ is attributable to the anomeric $\mathrm{C} 1$ carbon. Moreover, the signals at 62-64 ppm, clearly visible in all spectra (Fig. 1), and the less pronounced signals at $82-87 \mathrm{ppm}$, represent the C6 and $\mathrm{C} 4$ carbons of monomers attributable to crystalline and amorphous forms of cellulose, respectively [23]. Furthermore, the signals between 110 and $145 \mathrm{ppm}$, which mainly derive from unsubstituted and C-substituted aromatic carbons in either lignin monomers, lignans or flavonoids, showed a tendency to decrease with increasing depth in peat 1 , whereas they increased in peat 2 . No appreciable signals were observed in the region of esters or carboxyl groups (160-190 ppm), thus suggesting a small abundance of these moieties.

The spectra of residues (RES1-4) resulting from the humeomic fractionation showed a progressive depletion

Table2 Percent gravimetric distribution of different humeomic fractions, as related to the total organic matter contained in the bulk peat (RESO)

\begin{tabular}{llllllllll}
\hline Sample & ORG1 & ORG2 & AQU2 & ORG3 & AQU3 & ORG4 & AQU4 & RES4 & UM \\
\hline 1A $(27 \mathrm{~cm})$ & 6.20 & 16.00 & 10.80 & 0.45 & 2.25 & 7.10 & 3.69 & 12.35 & 41.16 \\
1B $(87 \mathrm{~cm})$ & 11.86 & 18.86 & 10.00 & 0.47 & 0.16 & 0.10 & 5.09 & 15.67 & 37.79 \\
2A $(27 \mathrm{~cm})$ & 7.72 & 11.47 & 6.40 & 1.54 & 0.74 & 1.73 & 2.59 & 30.06 \\
2B (101 cm) & 12.65 & 10.73 & 9.47 & 1.20 & 0.16 & 1.04 & 1.32 & 24.70 & 38.71 \\
\hline
\end{tabular}

UM unaccounted material 


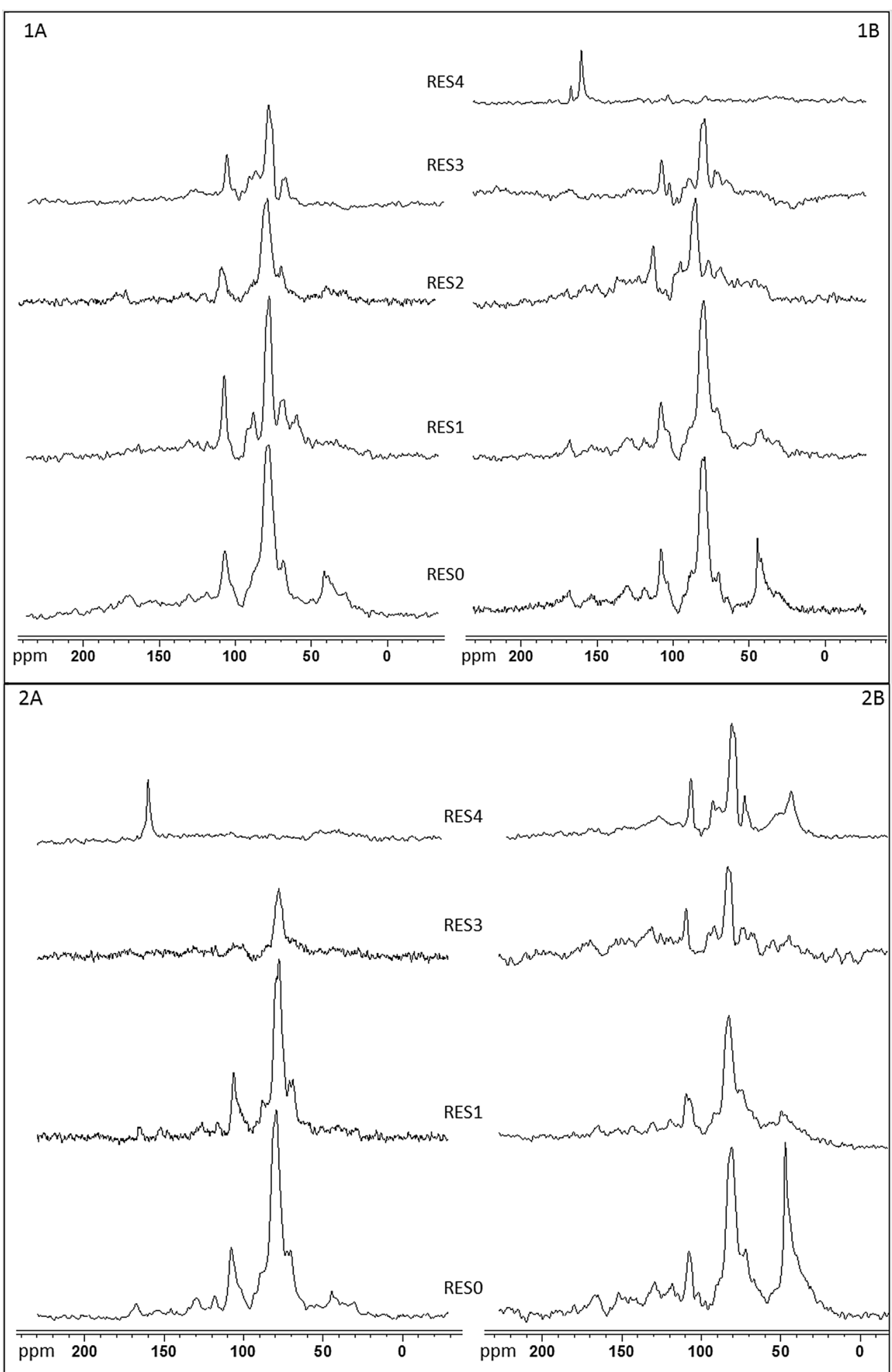

Fig. $1{ }^{13}$ C-CPMAS-NMR spectra of peat residues before (RESO) and after (RES1-4) humeomics. Samples codes are defined in Table 1 
Table 3 Relative abundance (\%) of chemical shift regions in ${ }^{13} \mathrm{C}$-CPMAS-NMR spectra of peat residues (RES0-RES4)

\begin{tabular}{|c|c|c|c|c|c|c|}
\hline & $\begin{array}{l}\text { Carboxyl-C } \\
(190-160)\end{array}$ & $\begin{array}{l}\text { Phenol-C } \\
(160-145)\end{array}$ & Aryl-C (145-110) & O-Alkyl-C (110-60) & Methoxyl-C (60-45) & $\begin{array}{l}\text { Alkyl-C } \\
(45-0)\end{array}$ \\
\hline \multicolumn{7}{|l|}{ Peat $1 \mathrm{~A}$} \\
\hline RES 0 & 5.28 & 3.20 & 9.10 & 59.31 & 6.43 & 16.68 \\
\hline RES 1 & 4.64 & 2.71 & 9.78 & 66.38 & 5.18 & 11.30 \\
\hline RES 2 & 2.81 & 3.46 & 12.80 & 62.26 & 10.43 & 8.24 \\
\hline RES 3 & 4.97 & 3.39 & 12.97 & 62.51 & 7.79 & 8.36 \\
\hline RES 4 & ND & ND & ND & ND & ND & ND \\
\hline \multicolumn{7}{|l|}{ Peat 1B } \\
\hline RES 0 & 4.08 & 3.77 & 13.45 & 54.67 & 5.83 & 18.20 \\
\hline RES 1 & 2.94 & 3.70 & 13.00 & 62.00 & 6.33 & 12.02 \\
\hline RES 2 & 0.69 & 3.35 & 17.39 & 53.58 & 11.72 & 13.27 \\
\hline RES 3 & 5.04 & 4.79 & 18.64 & 49.23 & 10.48 & 18.11 \\
\hline RES4 & 42.18 & 3.80 & 11.21 & 21.81 & 6.69 & 14.32 \\
\hline \multicolumn{7}{|l|}{ Peat 2A } \\
\hline RES 0 & 4.16 & 2.07 & 13.83 & 68.44 & 3.22 & 8.28 \\
\hline RES 1 & 0.95 & 2.07 & 9.00 & 76.54 & 4.79 & 6.65 \\
\hline RES 2 & ND & ND & ND & ND & ND & ND \\
\hline RES 3 & 7.87 & 5.47 & 14.09 & 56.38 & 6.80 & 9.40 \\
\hline RES4 & 29.01 & 6.42 & 16.90 & 17.74 & 4.50 & 25.44 \\
\hline \multicolumn{7}{|l|}{ Peat 2B } \\
\hline RES 0 & 3.21 & 3.46 & 11.81 & 44.76 & 7.13 & 29.73 \\
\hline RES 1 & 4.19 & 3.25 & 11.22 & 57.45 & 7.64 & 16.25 \\
\hline RES 2 & ND & ND & ND & ND & ND & ND \\
\hline RES 3 & 10.55 & 7.98 & 21.21 & 42.90 & 6.27 & 11.08 \\
\hline RES4 & 2.82 & 3.09 & 14.29 & 50.81 & 6.88 & 22.11 \\
\hline
\end{tabular}

ND not determined

of organic substances contained in the RESO bulk material. In particular, RES1 showed for all peat samples an evident reduction of signals in the alkyl-C region (0-45 ppm), whose components were extracted in the ORG1 fractions (Fig. 1, Table 3). This phenomenon was particularly relevant for the bottom layer of peat 2 , where the decrease was up to $45.4 \%$, whereas it was only $20 \%$ for the surface 2A layer. A similar trend, but to a smaller extent, was observed in the spectrum of RES1 of the Canadian peat, where the reduction was of 32 and 34\%, respectively, for $1 \mathrm{~A}$ and $1 \mathrm{~B}$, as compared to RESO.

The spectra of RES2 showed a reduction of signals in the $60-110$ ppm region by 6.3 and $13.6 \%$ for peat $1 \mathrm{~A}$ and $1 \mathrm{~B}$, respectively, as compared to RES1. The same peat samples also showed a reduction in the carboxyl-C signals by 40 and $77 \%$ (Fig. 1, Table 3). As for the Swiss peat, it was not possible to run the NMR spectrum of the RES2 because of its high hygroscopicity. The spectra of RES3 residues of both peat series (Fig. 1, Table 3) showed a reduction of signals usually attributed to either methoxyl carbons (mainly guaiacyl and syringyl units in lignin) or $\mathrm{C}-\mathrm{N}$ carbons in oligo- and poly-peptides. Evidently, these compounds were solubilized into AQU3 and ORG3 fractions.

Finally, the spectra of RES4 residues of the Swiss peat showed differences with depth (Fig. 1, Table 3). In fact, while the $2 \mathrm{~A}$ peat showed only an intense signal in the 160-190 ppm region after the HI treatment, the 2B sample revealed instead several other signals over the spectrum (Fig. 1), thereby indicating a significantly larger recalcitrance of the peat OM from the bottom layer compared to that from the surface. No spectrum could be acquired for RES4 of peat $1 \mathrm{~A}$, possibly due to the large presence of paramagnetic iron in this residue $[24,25]$.

\section{GC-MS characterization of ORG fractions}

The organo-soluble fractions (ORG1-4) extracted from both peat series were analyzed by GC-MS. The chromatographic profiles of each ORG fraction are shown in Additional file 1: Fig. S1, while the list of identified compounds in each fraction is reported in Additional file 1: Table S1. The chromatograms were highly reproducible among replicates and showed the differences among the ORG1-3 fractions for both peat series, whereas the 
material isolated in ORG4 resulted totally undetectable by GC-MS.

In general, the ORG1 and ORG3 fractions were mainly represented by fatty acids, while the ORG2 fractions showed a greater molecular heterogeneity enabling to differentiate peats on the basis of their geographical origin and depth (Additional file 1: Fig. S1, Table S1). The chromatograms of ORG2 fractions, besides a large abundance of fatty acids, also showed hydroxy acids, aromatic compounds, terpenoids and sugars, in variable amounts depending on the specific peat (Additional file 1: Fig. S1). In particular, both aromatic compounds and terpenoids in ORG2 showed opposite variations with depth, since they decreased significantly in the bottom layer for peat 1 , whereas they were enhanced with depth in peat 2 (Additional file 1: Fig. S1).

\section{Unbound fraction ORG1}

The GC-MS results for ORG1 fractions (Table 4) showed that, for both sites, the percent of identified compounds increased with depth, passing from 12.7 to $19.5 \%$ in peat 1 and from 6.8 to $31.4 \%$ in peat 2 . In all samples the most abundant class of compounds was represented by saturated medium-long chain fatty acids, in particular C16:0 and C18:0 (Table 4, Additional file 1: Table S1), whose amount, together with that of long chain hydroxy acids and linear alcohols, increased with depth. This trend was particularly relevant in the Swiss peat that showed an increase of saturated medium-long chain fatty acids, long chain hydroxy acids and linear alcohols by 218 , 716 and $316 \%$, respectively (Table 4 ). These enhancements, which occurred also in the $1 \mathrm{~B}$ peat, though by a lesser extent, were well in line with the reduction of
alkyl-C signals observed in NMR spectra of RES1 (Fig. 1, Table 3). The larger abundance of lipids in the bottom layers of peat may be due to the prevalent anaerobic conditions which limit microbial degradation [26].

The content of aromatic compounds also increased with depth in both peatlands, including the lignin cinnamic acid monomer, whose concentration was three and four times larger than in $1 \mathrm{~A}$ and $2 \mathrm{~A}$ the samples, respectively, thus indicating an enhanced lignin degradation in the surface peat layers (Table 4, Additional file 1: Table S1). This finding is in agreement with a previous study reporting that biodegradation in raised bog deposits occurs predominantly in the top layers of the peat where oxic conditions prevail, and that this process, mainly mediated by fungi and bacteria, is responsible for the initial decrease in phenolic constituents in peat samples [27]. Conversely, both peat series showed an opposite variation in terpenoids, whose content increased by $1640 \%$ in the $2 \mathrm{~B}$ sample compared to the $2 \mathrm{~A}$ sample, whereas the same compounds slightly decreased (13\%) with depth in peat 1 (Additional file 1: Fig. S1, Table 4). A small presence of both hexose and pentose sugars was also found in ORG1, whose content increased by 20 and $32 \%$ in the bottom layers of peat 1 and 2, respectively (Table 4).

\section{Weakly bound ester fraction ORG2}

The ORG2 fraction enabled a differentiation of peat samples based on depth. The cumulative amount of identified molecular components was 9.2, 7.6 and 7.0\% of total ORG2 by weight for samples $1 \mathrm{~A}, 1 \mathrm{~B}$ and $2 \mathrm{~A}$, respectively, while it rose to $31 \%$ for $2 \mathrm{~B}$ (Table 5 ). In peat 1 , an increasing depth meant an enhancement of saturated fatty

Table 4 GC-MS quantitative content of classes of compounds (expressed as $\mu \mathrm{g} \mathrm{g}^{-1}$ of extracted ORG1 fraction) in peat samples collected in two sites and at different depths. Standard deviation for three replicates is reported in parentheses

\begin{tabular}{lllll}
\hline Class of compounds & $\mathbf{1 A}$ & $\mathbf{1 B}$ & $\mathbf{2 A}$ & $\mathbf{2 B}$ \\
\hline Total sugars & $4302( \pm 628)$ & $5198( \pm 659)$ & $6582( \pm 2487)$ & $8729( \pm 1091)$ \\
$\quad$ Hexose & $1181( \pm 147)$ & $3072( \pm 291)$ & $2418( \pm 852)$ & $5989( \pm 647)$ \\
$\quad$ Pentose & $3120( \pm 481)$ & $2126( \pm 367)$ & $4164( \pm 1635)$ & $2740( \pm 444)$ \\
Total fatty acids & $85,753( \pm 9492)$ & $147,504( \pm 27,296)$ & $49,161( \pm 15,510)$ & $156,351( \pm 15,312)$ \\
$\quad$ Saturated & $78,647( \pm 9892)$ & $128,106( \pm 26,483)$ & $42,740( \pm 14,923)$ & $153,465( \pm 13,523)$ \\
$\quad$ Unsaturated & $7106( \pm 625)$ & $19,398( \pm 813)$ & $6421( \pm 588)$ & $2886( \pm 1789)$ \\
Hydroxy acids & $8601( \pm 1262)$ & $14,336( \pm 5008)$ & $3423( \pm 662)$ & $27,950( \pm 2122)$ \\
Dicarboxylic acids & $4164( \pm 295)$ & - & - & - \\
Linear alcohols & $2930( \pm 585)$ & $3362( \pm 738)$ & $1243( \pm 428)$ & $5177( \pm 376)$ \\
Total aromatic compounds & $3185( \pm 456)$ & $9462( \pm 1198)$ & $1933( \pm 576)$ & $8484( \pm 638)$ \\
$\quad$ Phenolic acids & $3185( \pm 456)$ & $6598( \pm 1023)$ & $6017( \pm 1802)$ & $8484( \pm 638)$ \\
Terpenoids & $18,097( \pm 5238)$ & $15,639( \pm 7074)$ & - & $104,688( \pm 10,896)$ \\
Alkanes & - & - & 68,358 & - \\
Total & 127,031 & 195,503 & & 311,380 \\
\hline
\end{tabular}


Table 5 GC-MS quantitative content of classes of compounds (expressed as $\mu \mathrm{g} \mathrm{g}^{-1}$ of extracted ORG2 fraction) in peat samples collected in two sites and at different depths. Standard deviation for three replicates is reported in parentheses

\begin{tabular}{lllll}
\hline Class of compounds & $\mathbf{1 A}$ & $\mathbf{1 B}$ & $\mathbf{2 A}$ & $\mathbf{2 B}$ \\
\hline Total sugars & $5879( \pm 879)$ & $16,000( \pm 5262)$ & $7262( \pm 928)$ & $41,623( \pm 2454)$ \\
$\quad$ Hexose & $764( \pm 30)$ & $6955( \pm 2213)$ & $1512( \pm 203)$ & $11,006( \pm 672)$ \\
$\quad$ Pentose & $5115( \pm 848)$ & $9045( \pm 3050)$ & $5749( \pm 725)$ & $30,617( \pm 1783)$ \\
Total fatty acids & $21,137( \pm 700)$ & $57,753( \pm 44,313)$ & $29,376( \pm 16,005)$ & $21,263( \pm 2653)$ \\
$\quad$ Saturated & $19,236( \pm 657)$ & $49,799( \pm 39,349)$ & $22,073( \pm 11,411)$ & $21,263( \pm 2653)$ \\
$\quad$ Unsaturated & $1901( \pm 43)$ & $7954( \pm 4964)$ & $7303( \pm 4594)$ & - \\
Hydroxy acids & $28,157( \pm 3136)$ & - & $14,008( \pm 2930)$ & $32,679( \pm 2002)$ \\
Dicarboxylic acids & $6594( \pm 192)$ & - & $548( \pm 72)$ & - \\
Linear alcohols & - & - & - & - \\
Total aromatic compounds & $26,157( \pm 1815)$ & - & $18,329( \pm 2388)$ & $142,396( \pm 1932)$ \\
$\quad$ Phenolic acids & $15,359( \pm 1140)$ & - & $1154( \pm 258)$ & $122,550( \pm 7935)$ \\
Terpenoids & $4251( \pm 1072)$ & $2342( \pm 603)$ & - & $69,184( \pm 27,128)$ \\
Alkanes & - & - & 70,677 & - \\
Total & 92,175 & 76,095 & & 307,136 \\
\hline
\end{tabular}

acids and sugars, reaching for both compounds a relative enrichment of about $170 \%$ compared to the surface layer. These data were in line with the NMR spectra of RES2, where a decrease in O-alkyl signals was observed. All other molecular classes of ORG2 present in 1A were almost undetectable in $1 \mathrm{~B}$, showing an opposite trend in comparison to that observed in ORG1, possibly due to a greater difficulty in derivatization and consequent poor detection of specific molecular components present in this extract. As for the Swiss peat, the content of fatty acids did not change with sampling depth, whereas the sugar components showed a similar behavior as the
Canadian peat, revealing a significant $473 \%$ enhancement with depth.

These results suggest that, in both cases, the transesterification reaction following the breakdown of ester bonds facilitated the release of hydrophilic compounds which had been trapped in the hydrophobic domains of the supramolecular matrix. An opposite behavior between the two peat series resided in the content of hydroxy acids, aromatic and terpenoids compounds, which increased with depth by 133, 676 and even $5896 \%$, respectively. In particular, the aromatic compounds, represented mainly by benzoic derivatives or phenolic compounds of lignin origin, confirmed

Table 6 GC-MS quantitative content of classes of compounds (expressed as $\mu \mathrm{g} \mathrm{g}^{-1}$ of extracted ORG3 fraction) in peat samples collected in two sites and at different depths. Standard deviation for three replicates is reported in parentheses

\begin{tabular}{lllll}
\hline Class of compounds & $\mathbf{1 A}$ & $\mathbf{1 B}$ & $\mathbf{2 A}$ & $\mathbf{2 B}$ \\
\hline Total sugars & - & $173( \pm 2)$ & $479( \pm 3)$ & - \\
$\quad$ Hexose & - & - & - & - \\
$\quad$ Pentose & - & $173( \pm 1)$ & $479( \pm 4)$ & - \\
Total fatty acids & $59,179( \pm 4417)$ & $133,159( \pm 17,152)$ & $315,631( \pm 10,077)$ & $260,912( \pm 40,136)$ \\
$\quad$ Saturated & $52,049( \pm 4179)$ & $101,237( \pm 13,649)$ & $281,373( \pm 10,013)$ & $199,903( \pm 27,455)$ \\
$\quad$ Unsaturated & $7129( \pm 239)$ & $31,922( \pm 3503)$ & $34,258( \pm 64)$ & $61,009( \pm 12,681)$ \\
Hydroxy acids & - & - & $4317( \pm 43)$ & $1884( \pm 459)$ \\
Dicarboxylic acids & $114( \pm 5)$ & $583( \pm 33)$ & $4328( \pm 63)$ & - \\
Linear alcohols & - & - & $355( \pm 12)$ & - \\
Total aromatic compounds & - & $4666( \pm 391)$ & $6488( \pm 181)$ & $22,372( \pm 4133)$ \\
$\quad$ Phenolic acids & - & - & - & $115,332( \pm 546)$ \\
Terpenoids & $18,727( \pm 1566)$ & $10,341( \pm 2992)$ & $2059( \pm 48)$ & $16,744( \pm 2753)$ \\
Alkanes & - & - & $72,758( \pm 712)$ & - \\
Total & 78,020 & 148,923 & 406,417 & 301,912 \\
\hline
\end{tabular}


the large degree of degradation of this biopolymer. Therefore, the different concentration of these ligninderived molecules represented the main differentiation between the two peat series under study, although both consisted mainly of Sphagnum residues [17, 18, 27].

\section{Strongly bound ester fraction ORG3}

The percentage of compounds identified in ORG3 indicated an opposite trend with depth in the two peat series (Table 6). The particularly low value in $1 \mathrm{~A}$ peat was doubled in peat $1 \mathrm{~B}$, whereas it decreased from 40 to $30 \%$ in peat 2 . The alkaline transesterification reaction solubilized in ORG3 a large quantity of medium and long chain linear fatty acids (C16-C28) for both peat series. In particular, these compounds increased by $125 \%$ passing from $1 \mathrm{~A}$ to $1 \mathrm{~B}$ samples. Conversely, a change of the same compounds with depth was not significant in peat 2 . The second most abundant class of compounds in peat $2 \mathrm{~A}$ was that of alkanes with almost $20 \%$ of the total molecular content, whereas these compounds were hardly detectable in other peat samples. Aromatic compounds increased with depth in both peat series, resulting particularly abundant in $2 \mathrm{~B}$ as benzoic and phenolic derivatives. Finally, terpenic compounds showed a contrasting trend with depth, since they decreased in peat 1 but increased by $700 \%$ in peat 2 .

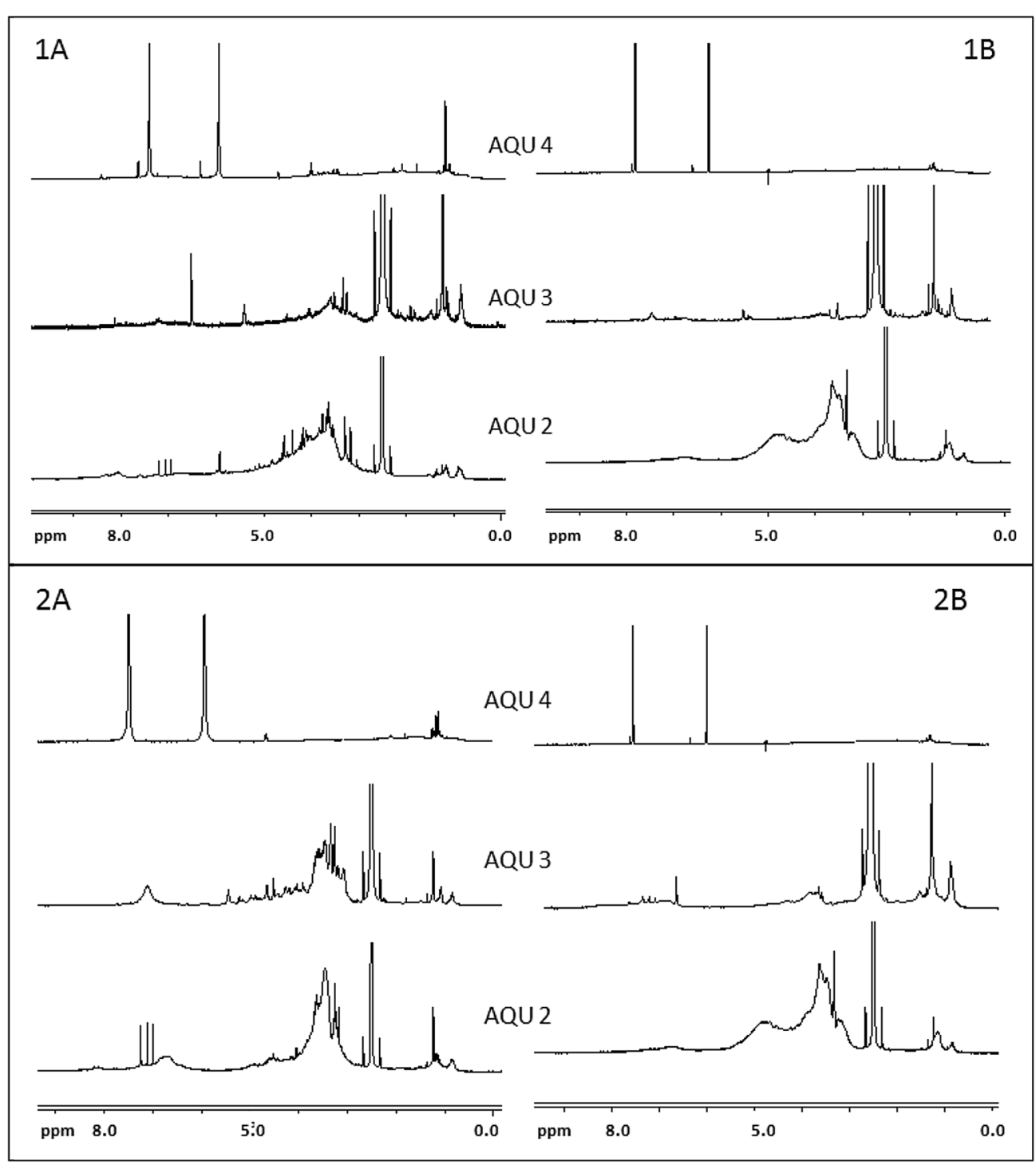

Fig. 2: ${ }^{1} \mathrm{H}$ NMR of water-soluble fraction (AQU2-4) solubilized by humeomics. Samples codes are defined in Table 1 


\section{Characterization of AQU fractions by ${ }^{1} \mathrm{H}-\mathrm{NMR}$}

The ${ }^{1} \mathrm{H}-\mathrm{NMR}$ spectra of the AQU fractions of both Canadian and Swiss peats at different depth are shown in Fig. 2. The AQU4 spectral profiles of both peat series showed a certain similarity, whereas both AQU2 and AQU3 differed according to depth (Fig. 2). The proton spectra of AQU2 factions were characterized by intense signals in the O-alkyl region (3-5 ppm) suggesting the presence of carbohydrates or other highly hydroxylated compounds. This resonance region remained conspicuous in the AQU3 fractions of both $1 \mathrm{~A}$ and $2 \mathrm{~A}$ peats, while it decreased with depth in both peat series leaving predominant only the signals attributable to methylene and methyl groups of short chain fatty acids, including unsaturated, mono or poly-hydroxylated chains (Fig. 2).

Some signals of low intensity related to aromatic compounds (6-8 ppm), and mainly due to lignin phenols solubilized by the BF3 transesterification treatment, were visible in AQU2 fractions in all peat samples. The particular quadrupolic triplet at $7 \mathrm{ppm}$ was instead attributed to ammonium ions, being distinctive of the AQU2 fraction of the surface peat layers.

\section{Conclusions}

The application of humeomics to peat samples collected in two different Countries (Canada and Swiss) and at different depths revealed specific differences in molecular composition among samples, although they did not differ significantly in terms of elemental composition.

Independently of the site and depth, the fractionation process allowed the extraction of three organo-soluble (ORG1-ORG3) and three water-soluble (AQU2-AQU4) fractions, which were less heterogeneous than the bulk material and whose molecular characterization was therefore relatively simpler and more complete.

The three ORG fractions consisted mainly of aliphatic compounds and, to a lesser extent, aromatic and sugar compounds, whose concentrations were characteristic of each peat sample. The AQU fractions instead showed an abundance of carbohydrates or other highly hydroxylated compounds attributable to short chain aliphatic compounds that showed large variation mainly with depth. Furthermore, the diverse extraction yields of fractions suggested a different degree of accessibility to the solubilization of specific organic compounds in the two peat series.

Our findings indicate that the humeomics applied to natural materials rich in $\mathrm{OM}$, such as peats, provides not only information on the extractive quantity of the different fraction, but also on the strength by which the solubilized organic compounds were retained in the complex supramolecular structure of peat humus. "However, this study also points out that more specific information on the molecular composition of these terrestrial humic-rich samples can be reached when advanced highresolution analytical techniques are applied for their characterization.

\section{Supplementary information}

Supplementary information accompanies this paper at https://doi. org/10.1186/s40538-020-00184-6.

Additional file 1: Table S1. Molecules identified in chromatograms of ORG 1-3 fractions at different Retention Times. Figure S1. Chromatograms of organo-soluble fractions (ORG 1-3) solubilized during the Humeomic fractionation.

\section{Abbreviations}

AQU: Hydrosoluble fraction; BBI: Broadband inverse probe; ${ }^{13} \mathrm{C}-\mathrm{CPMAS}-N M R$ : ${ }^{13} \mathrm{C}$ cross-polarization magic-angle-spinning nuclear magnetic resonance spectroscopy; DMSO-d6: Deuterated dimethyl sulfoxide; El: Electron impact; FID: Free induction decays; GC-MS: Gas chromatography-mass spectrometry; GtC: Gigatons of carbon; ${ }^{1} \mathrm{H}$ NMR: Proton nuclear magnetic resonance spectroscopy; OM: Organic matter; ORG: Organosoluble fraction; RES: Residue fraction.

\section{Acknowledgements}

The authors thank Prof. William Shotyk, University of Alberta, Canada, for providing Queen Charlotte Islands samples.

\section{Authors' contributions}

GV performed the Humeomic fractionation on peat samples, analyzed and interpreted the GC-MS data and was the major contributor in writing the manuscript. PM performed all NMR analyses and contributed to the interpretation of NMR data. MD contributed to the interpretation of the GC-MS data and to the discussion in the manuscript. CZ provided the peat samples, and contributed to write and review the manuscript. AP conceived and designed the experiment, was the supervisor of all phases of data analysis and interpretation, coordinated the work of the co-authors and reviewed the entire manuscript. All authors read and approved the final manuscript.

Funding

No funding was received.

\section{Availability of data and materials}

All data generated or analyzed during this study are available from the corresponding author on reasonable request.

Ethics approval and consent to participate Not applicable.

Consent for publication

Not applicable.

\section{Competing interests}

The authors declare that they have no competing interests.

\section{Author details}

${ }^{1}$ Centro Interdipartimentale di Ricerca Sulla Risonanza Magnetica Nucleare per l'Ambiente, I'Agroalimentare ed i Nuovi Materiali (CERMANU), Università di Napoli Federico II, Via Università, 100, 80055 Portici, NA, Italy. ${ }^{2}$ College of Resources and Environmental Sciences, Nanjing Agricultural University, Nanjing, China. ${ }^{3}$ Department of Biotechnology, University of Verona, Strada Le Grazie 15, 37134 Verona, Italy.

Received: 10 January 2020 Accepted: 11 March 2020

Published online: 25 September 2020 


\section{References}

1. Johnson L, Damman AWH. Decay and its regulation in Sphagnum peatlands. Adv Bryol. 1993;5:249-96.

2. Kelly TJ, Lawson IT, Cole LES. Peat. In: White WM, editor. Encyclopedia of geochemistry encyclopedia of earth sciences series. Springer: Cham; 2018. p. 1197-1200

3. Shotyk W. Review of the inorganic geochemistry of peats and peatland waters. Earth Sci Rev. 1988;25:95-176.

4. Puglisi E, Zaccone C, Cappa F, Cocconcelli PS, Shotyk W, Trevisan M, Miano TM. Changes in bacterial and archaeal community assemblages along an ombrotrophic peat bog profile. Biol Fertil Soils. 2014;50:815-26.

5. Concheri G, Stevanato P, Zaccone C, Shotyk W, D'Orazio V, Miano T, Piffanelli P, Rizzi V, Ferrandi C, Squartini A. Rapid peat accumulation favours the occurrence of both fen and bog microbial communities within a Mediterranean, free-floating peat island. Scientific Rep. 2017;7:8511.

6. Kuhry $\mathrm{P}$, Vitt DH. Fossil carbon/nitrogen ratios as a measure of peat decomposition. Ecology. 1996;77:271-5.

7. Barber KE, Chambers FM, Maddy D. Holocene palaeoclimates from peat stratigraphy: macrofossil proxy-climate records from three oceanic raised bogs in England and Ireland. Quatern Sci Rev. 2003:22:521-39.

8. Bragazza L, Buttler A, Robroek BJM, Albrecht R, Zaccone C, Jassey VEJ, Signarbieux C. Persistent high temperature and low precipitation reduce peat carbon accumulation. Glob Change Biol. 2016;22:4114-233.

9. Zaccone C, Plaza C, Ciavatta C, Miano TM, Shotyk W. Advances in the determination of humification degree in peat since Achard (1786): applications in geochemical and paleoenvironmental studies. Earth Sci Rev. 2018;185:163-78.

10. Clymo RS. Peat. In: Gore AJP, editor. Mires: swamp, bog, fen and moor, ecosystems of the world. 4th ed. New York: Elsevier Scientific Publishing Co; 1983. p. 159-224.

11. Clymo RS. The limits of peat growth. Proceedings of the Royal Society, London: Series B. 1984; Vol. 303, p. 605654

12. Yu Z, Loisel J, Brosseau DP, Beilman DW, Hunt SJ. Global peatland dynamics since the last glacial maximum. Geophys Res Lett. 2010;37:1-5.

13. Charman DJ. Peatlands and environmental change. West Sussex: Wiley; 2002. p. 312.

14. Kogel-Knabner I. Analytical approaches for characterizing soil organic matter. Org Geochem. 2000;31:609-25.

15. Nebbioso A, Piccolo A. Basis of a Humeomics Science: chemical fractionation and molecular characterization of humic biosuprastructures. Biomacromolecule. 2011;12:1187-99.

16. Drosos M, Nebbioso A, Mazzei P, Vinci G, Spaccini R, Piccolo A. A molecular zoom into soil Humeome by a direct sequential chemical fractionation of soil. Sci Total Environ. 2017:15:807-16.
17. Huntley MJ, Mathewes RW, Shotyk W. High-resolution palynology, climate change and human impact on a late Holocene peat bog on Haida Gwaii, British Columbia, Canada. Holocene. 2013:23:1572-83.

18. Zaccone C, Gallipoli A, Cocozza C, Trevisan M, Miano TM. Distribution patterns of selected PAHs in bulk peat and corresponding humic acids from a Swiss ombrotrophic bog profile. Plant Soil. 2009;315:35-45.

19. Waksman SA. Influence of microorganisms upon the carbon-nitrogen ratio in soil. J Agric Sci. 1924;14:555-62.

20. Waksman SA, Tenney FG. The Composition of natural organic materials and their decomposition in the soil: II. Influence of age of plant upon the rapidity and nature of its decomposition-rye plants. F G Soil Sci. 1927;24:317.

21. Deshmukh AP, Simpson AJ, Hadad CM, Hatcher PG. Insights into the structure of cutin and cutan from Agave americana leaf cuticle using HRMAS NMR spectroscopy. Org Geochem. 2005;36:1072-85.

22. De Marco A, Spaccini R, Vittozzi P, Esposito F, Berg B, Virzo DeSanto A. Decomposition of black locust and black pine leaf litter in two coeval forest stands on Mount Vesuvius and dynamics of organic components assessed through proximate analysis and NMR spectroscopy. Soil Biol Biochem. 2012:51:1-15.

23. Spaccini R, Piccolo A. Molecular characteristics of humic acids extracted from compost at increasing maturity stages. Soil Biol Biochem. 2009:41:1164-72.

24. Drosos M, Piccolo A. The molecular dynamics of soil humus as a function of tillage. Land Degrad Dev. 2018;29:1792-805.

25. Drosos M, Savy D, Spiteller M, Piccolo A. Structural characterization of carbon and nitrogen molecules in the Humeome of two different grassland soils. Chem Biol Technol Agric. 2018;5:14

26. Pancost RD, McClymont EL, BinGham EM, Roberts Z, Charman DJ. Org Geochem. 2011;42:1279-87.

27. Zaccone C, Said-Pullicino D, Gigliotti G, Miano TM. Diagenetic trends in the phenolic constituents of Sphagnum-dominated peat and its corresponding humic acid fraction. Org Geochem. 2008:39:830-8.

\section{Publisher's Note}

Springer Nature remains neutral with regard to jurisdictional claims in published maps and institutional affiliations.

\section{Submit your manuscript to a SpringerOpen ${ }^{\circ}$ journal and benefit from:}

- Convenient online submission

- Rigorous peer review

- Open access: articles freely available online

- High visibility within the field

Retaining the copyright to your article

Submit your next manuscript at springeropen.com 